Supporting Information for

\title{
An Experimental and Theoretical Study of Laser Postionization of Femtosecond Laser Desorbed Drug Molecules
}

\author{
Cornelius L. Pieterse, Ivan Rungger, and Ian S. Gilmore \\ National Physical Laboratory, Hampton Road, Teddington, TW11 0LW UK \\ Raveendra C. Wickramasinghe and Luke Hanley* \\ Department of Chemistry, University of Illinois at Chicago, Chicago, IL 60607 USA \\ Corresponding author email: LHanley@uic.edu
}

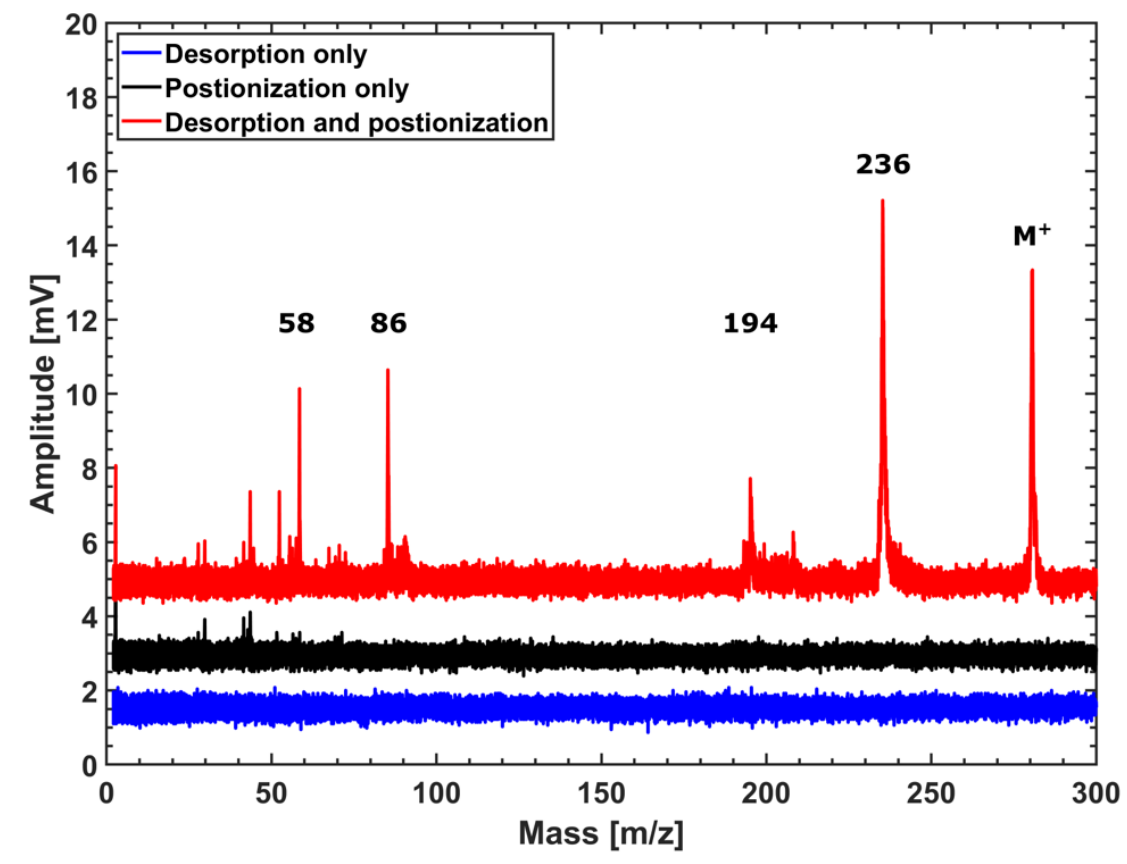

Figure S1. $f s-L D P I-M S$ (red), $f s-L D I$ (blue), and $7.9 \mathrm{eV}$ laser postionization (black) only of imipramine.

Impact of desorption laser fluence on fragmentation. The primary focus of this work is to explore threshold single photon ionization of neutral drug molecules in the gas-phase. However, it is also useful to explore the unique characteristics of using fs-laser desorption (fs-LD) to volatilize these molecules. The same methodology was followed here as described in previous studies: ${ }^{1,2}$ the survival yields were calculated as $S=$ $I_{M} /\left(I_{M}+I_{F}\right)$, where $I_{M}$ and $I_{F}$ are the integrated abundances of the molecular and fragment ion intensities, respectively. The mean survival yields were determined by averaging the survival yield distributions and assumes that all ions have the same detection efficiency. ${ }^{3}$ The overall softness of the desorption process was determined here by measuring the survival yield as a function of desorption laser fluence. The concept of using 
survival yields assumes that a single unimolecular dissociation is represented by the mass spectrum. Figure S2 shows the survival yields for imipramine during fs-LDPI-MS, where (top) shows the survival yield as a function of fluence, and (bottom) shows the survival yield distribution for the highest fluence measured. The measurement repeatability was determined by calculating the average signal intensity $I$ and survival yields $S$ of five carbamazepine samples $(I=56 \pm 12 \mathrm{mV}$ and $S=0.47 \pm 0.07)$. It is well-established that even for samples which are prepared in the same fashion, there tends to be considerable variability in the absolute signal intensity of nanosecond laser desorption/ionization. ${ }^{4,5}$

There have been only a limited number of studies investigating the application of femtosecond pulses for desorption/ablation in MS imaging. ${ }^{6-11}$ The most striking observation here is that, for the fluence range studied, the fragmentation did not change with desorption laser fluence, staying constant at $S \sim 0.26$. The survival yield histogram structure, also shown in Figure S2 (top), indicated a fluence independence that would enhance measurement repeatability. Although signal intensity variations for each individual measurement (sample) were observed, the variability of the mean for the different measurements was acceptable (standard Gaussian statistics are used to calculate the error bars). Prior results for $800 \mathrm{~nm}$ fs-LD found ranges of laser fluence over which survival yields were relatively constant, ${ }^{7}$ but the survival yields did eventually vary at sufficiently low or high fluences. ${ }^{7,9}$ Prior work has shown the ability of fs-LDPI-MS (using $10.5 \mathrm{eV}$ single photon ionization) and fs-LDI-MS (without using postionization) to transfer similar amounts of internal energy to a precursor ion as vacuum-based matrix assisted laser desorption ionization MS. ${ }^{7}$ Other aspects of the fs-LD process and how it can be coupled to single photon ionization for fs-LDPI-MS imaging have been discussed elsewhere. ${ }^{8,9,11}$ Overall, the results of Figure S2 are intriguing, given that nanosecond pulsed laser-based desorption techniques typically depend nonlinearly on laser fluence. ${ }^{12,13}$ Nevertheless, further experiments are required to explore the dependence of fragmentation on laser fluence in fs-LD and its impact on shot-to-shot reproducibility.

Many of the peaks between m/z 50 and 60 in the $7.9 \mathrm{eV}$ fs-LDPI-MS of Figure $3 \backslash 4$ are from the underlying metal substrate while a $\mathrm{Cs}^{+}$peak shown in Figure 4(a) arose from the presence of added CsI calibrant. This can be seen in the mass spectra in Figure S3 in which an enhancement of ion signals is associated with the stainless-steel substrate at high laser fluence, consistent with an earlier study. ${ }^{9}$ 

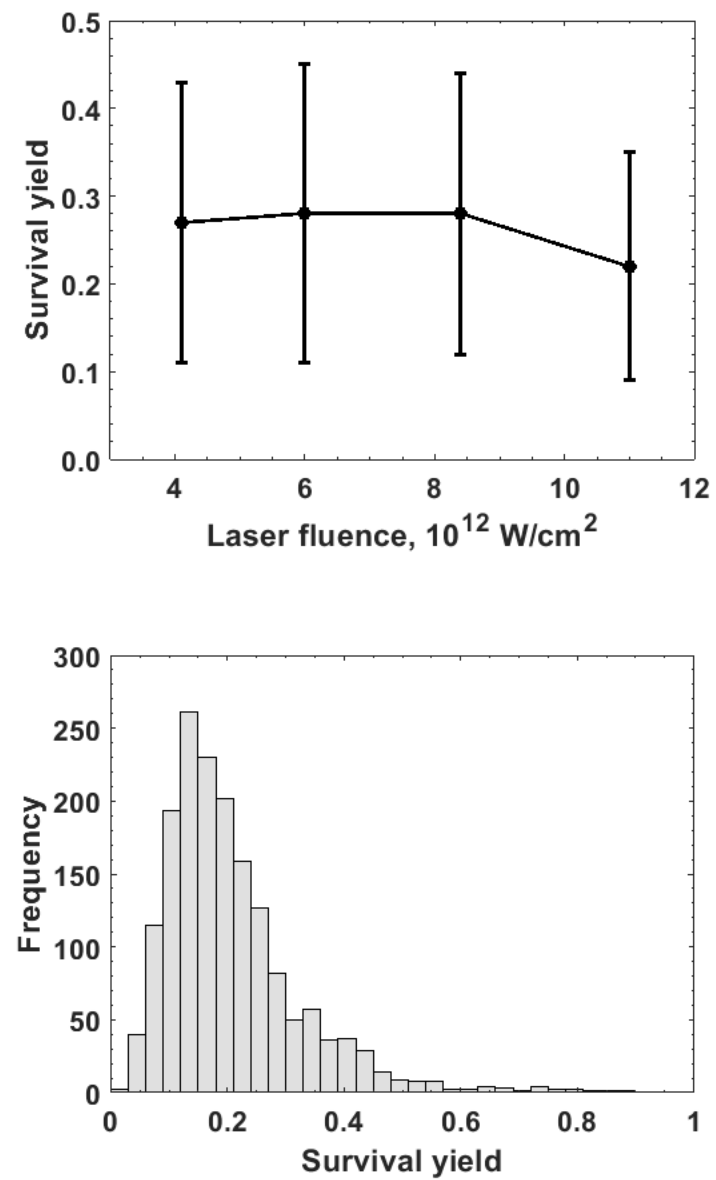

Figure S2. (Top) Mean survival yield for the fluence range studied for $7.9 \mathrm{eV} f_{s-L D P I-M S}$ of imipramine. (Bottom) Survival yield distribution of imipramine for the highest fluence $\left(1.1 \times 10^{13} \mathrm{~W} / \mathrm{cm}^{2}\right)$.
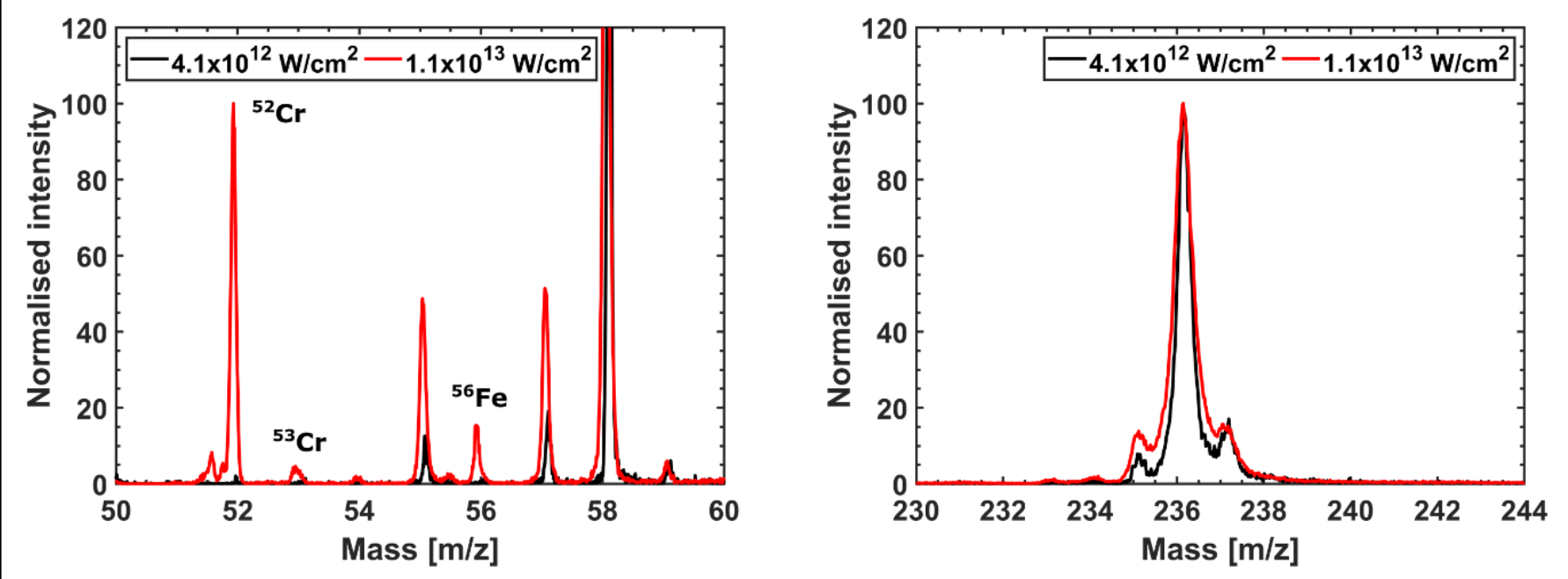

Figure S3. fs-LDPI-MS of imipramine for the lowest and highest desorption laser fluences $\left(4.1 \times 10^{12} \mathrm{~W} / \mathrm{cm}^{2}\right.$ and $\left.1.1 \times 10^{13} \mathrm{~W} / \mathrm{cm}^{2}\right)$ emphasizing peaks originating from the stainless-steel substrate (left) and a fragment of imipramine (right). 
Table S1. GGA Kohn-Sham energy differences for the six highest occupied molecular orbitals (HOMOs).

\begin{tabular}{|l|l|l|l|l|}
\hline & Carbamazepine & Ciprofloxacin & Verapamil & Imipramine \\
\hline$E_{\text {номо }}-E_{\text {номо-1 }}(\mathrm{eV})$ & 0.16 & 0.31 & 0.08 & 0.45 \\
& & & & \\
\hline$E_{\text {номо }} E_{\text {номо-2 }}(\mathrm{eV})$ & 0.51 & 0.54 & 0.19 & 1.36 \\
\hline$E_{\text {номо }}-E_{\text {номо-3 }}(\mathrm{eV})$ & 0.82 & 0.63 & 0.91 & 1.51 \\
\hline$E_{\text {номо }}-E_{\text {номо-4 }}(\mathrm{eV})$ & 1.09 & 1.00 & 1.06 & 1.63 \\
\hline$E_{\text {номо }}-E_{\text {номо-5 }}(\mathrm{eV})$ & 1.37 & 1.57 & 2.36 & 2.28 \\
\hline
\end{tabular}

Comparison of Highest and Nearby Occupied Molecular Orbitals. Density functional theory (DFT) was performed with the semi-local exchange correlation functionals GGA and LDA. The negative of the KohnSham energy eigenvalue for the highest occupied molecular orbital (HOMO) - Еномо - typically underestimates the experimental ionization energy (IE) such that $\mathrm{E}_{\mathrm{HOMO}}<$ IE. However, the shape of the HOMO wave function is usually captured correctly by this procedure. Thus, the shape of the HOMO wavefunctions in Figure 3 are generally accurate, but the relative energy differences between HOMO and HOMO-1, as shown in Table S1, are underestimated.

\section{References for Supporting Information}

(1) Luo, G.; Marginean, I.; Vertes, A. Internal energy of ions generated by matrix-assisted laser desorption/ionization. Analytical Chemistry 2002, 74, 6185-6190.

(2) Luo, G.; Marginean, I.; Ye, L.; Vertes, A. Competing ion decomposition channels in matrix-assisted laser desorption ionization. The Journal of Physical Chemistry B 2008, 112, 6952-6956.

(3) Gilmore, I.; Seah, M. P. Ion detection efficiency in SIMS: Dependencies on energy, mass and composition for microchannel plates used in mass spectrometry. International Journal of Mass Spectrometry 2000, 202, 217-229.

(4) Vorm, O.; Roepstorff, P.; Mann, M. Improved resolution and very high sensitivity in MALDI ToF of matrix surfaces made by fast evaporation. Analytical Chemistry 1994, 66, 3281-3287.

(5) Ahn, S.; Park, K.; Bae, Y.; Kim, M. Efficient methods to generate reproducible mass spectra in matrixassisted laser desorption ionization of peptides. Journal of the American Society for Mass Spectrometry 2013, 24, 868-876.

(6) Flanigan, P.; Levis, R. Ambient femtosecond laser vaporization and nanosecond laser desorption electrospray ionization mass spectrometry. Annual Review of Analytical Chemistry 2014, 7, 229-256. 
(7) Milasinovic, S.; Cui, Y.; Gordon, R. J.; Hanley, L. Internal energy of thermometer ions formed by femtosecond laser desorption: Implications for mass spectrometric imaging. Journal of Physical Chemistry C 2014, 118, 28938-28947.

(8) Cui, Y.; Bhardwaj, C.; Milasinovic, S.; Carlson, R. P.; Gordon, R. J.; Hanley, L. Molecular imaging and depth profiling of biomaterials interfaces by femtosecond laser desorption postionization mass spectrometry. ACS Applied Materials \& Interfaces 2013, 5, 9269-9275.

(9) Cui, Y.; Veryovkin, I. V.; Majeski, M. W.; Cavazos, D. R.; Hanley, L. High lateral resolution vs. molecular preservation in near-IR fs-laser desorption postionization mass spectrometry. Analytical Chemistry 2015, 87, 367-371.

(10) Walker, A. V.; Gelb, L. D.; Barry, G. E.; Subanajouy, P.; Poudel, A.; Hara, M.; Veryovkin, I. V.; Bell, G. I.; Hanley, L. Femtosecond laser desorption ionization mass spectrometry imaging and multivariate analysis of lipids in pancreatic tissue. Biointerphases 2018, 13, 03B416.

(11) Hanley, L.; Wickramasinghe, R.; Yung, Y. P. Laser sampling combined with laser postionization for mass spectrometry. Annual Review of Analytical Chemistry 2019, 12, 225-245.

(12) Dreisewerd, K.; Schürenberg, M.; Karas, M.; Hillenkamp, F. Influence of the laser intensity and spot size on the desorption of molecules and ions in matrix-assisted laser desorption/ionization with a uniform beam profile. International Journal of Mass Spectrometry and Ion Processes 1995, 141, 127-148.

(13) Dreisewerd, K. Recent methodological advances in MALDI mass spectrometry. Analytical and Bioanalytical Chemistry 2014, 406, 2261-2278. 